\title{
Development of a cartilage composite utilizing porous tantalum, fibrin, and rabbit chondrocytes for treatment of cartilage defect
}

\author{
Kamal Jamil ${ }^{1 *}$, Kien-Hui Chua ${ }^{2}$, Samad Joudi ${ }^{1}$, Sook-Luan $\mathrm{Ng}^{2}$ and Nor Hamdan Yahaya ${ }^{1}$
}

\begin{abstract}
Objective: Functional tissue engineering has emerged as a potential means for treatment of cartilage defect. Development of a stable cartilage composite is considered to be a good option. The aim of the study was to observe whether the incorporation of cultured chondrocytes on porous tantalum utilizing fibrin as a cell carrier would promote cartilage tissue formation.
\end{abstract}

Methods: Rabbit articular chondrocytes were cultured and seeded onto tantalum with fibrin as temporary matrix in a composite, which was divided into three groups. The first group was kept in vitro while a total of 12 constructs were implanted into the dorsum of mice for the second and third groups. The implanted tissues were harvested after 4 weeks (second group) and after 8 weeks (third group). Specific characteristic of cartilage growth were studied by histological and biochemical assessment, immunohistochemistry, and quantitative PCR analysis.

Results: Histological and biochemical evaluation of the formed cartilage using hematoxylin and eosin and Alcian blue staining showed lacunae chondrocytes embedded in the proteoglycan rich matrix. Dimethylmethylene blue assay demonstrated high glycosaminoglycans content in the removed tissue following 8 weeks of implantation. Immunohistochemistry results showed the composites after implantation expressed high collagen type II.

Quantitative PCR results confirmed a significant increase in cartilage associated genes expression (collagen type II, AggC, Sox 9) after implantation.

Conclusion: Tantalum scaffold with fibrin as cell carrier promotes chondrocyte proliferation and cartilaginous tissue formation. Producing hyaline cartilage within a stable construct of tantalum and fibrin has a potential for treatment of cartilage defect.

Keywords: Cartilage composite, Porous tantalum, Chondrocyte proliferation, Cartilage defect, Fibrin

\section{Introduction}

Around two million individuals are affected worldwide with arthritis [1]. These individuals require hospitalization, which is a matter of concern. Total joint replacement is the usual end-stage treatment, but implant longevity is an issue as more than half of the affected individuals is below 65 years old [2-7]. Damage to articular cartilage leads to premature arthritis. This chondral lesion was reported to be present in $60 \%$ of all patients aged between $40-50$ years during arthroscopy $[1,7,8]$. Due to its avascular nature and

\footnotetext{
*Correspondence: drkortho@gmail.com

'Department of Orthopaedic and Traumatology, Faculty of Medicine, Universiti Kebangsaan Malaysia, Jalan Yaacob Latiff, Bandar Tun Razak, 56000 Cheras, Kuala Lumpur, Malaysia

Full list of author information is available at the end of the article
}

ineffective response to injury, articular cartilage has limited potential to heal, even so in larger defects. Partial thickness injuries do not heal and merely stimulate minimal reaction to adjacent chondrocytes in the form of cell replication and matrix turnover, whereas full thickness injuries penetrating subchondral bone produce normal healing response but eventually fills the defect with fibrocartilage [9]. Fibrocartilage resists to tension, in contrast to normal hyaline cartilage which resists compressive forces. Therefore, there is an urgent need for a method for effective biological healing and regeneration of cartilage to prevent premature arthritis.

There are various methods of operative treatment employed to treat osteochondral injury. Marrow stimulation and resurfacing techniques have been advocated but 
they have their limitations while dealing with large defects and producing hyaline cartilage [9-15]. Autologous chondrocyte implantation (ACI) which was brought into attention by Brittberg et al. in 1994 is quite promising but this technique is expensive and highly technically dependent [10]. It requires two surgeries and needs laboratory support to grow the cells [13].

Functional tissue engineering is a novel approach to enhance tissue regeneration and provides the possibility of producing tissue that is biomechanically, biochemically, and histomorphologically similar to the native tissues [7]. Scientists and engineers working in this promising field are taking steps to make those ideas a reality, working to supply biological substitutes or living tissue. A previous study by Munirah et al. for articular cartilage restoration focused on engineering autologous cartilage construct using human and ovine chondrocytes incorporated with the autologous fibrin as biomaterial [16]. The pre-clinical study, conducted in sheep, was designed to evaluate the performance of the autologous 'chondrocytes-fibrin' construct implantation in a simulated clinical application prior to undertaking the definitive pre-clinical and clinical investigations. However, it has its own limitation. Resulted 'chondrocytes-fibrin' constructs were too soft to hold into the defect independently. Technically, periosteal patch were used to secure the implant into the defect.

There is continuous quest for the development of a new and more reliable technique to restore or reconstruct osteochondral defects. The development of a composite with the biochemical and mechanical properties of an osteochondral graft with better integration properties and without the need for autologous osteochondral graft harvesting or allogeneic tissue would be attractive. Tantalum, an elemental metal which is strong, biocompatible, and corrosive-resistant, has been widely used in the field of orthopedics due to its low modulus of elasticity and low frictional characteristics. It also has high, interconnected porosity with excellent bone in growth properties. In the present study, we incorporated cultured chondrocytes on porous tantalum utilizing fibrin as a cell carrier to support in vitro chondrogenesis. Following this, we compared it with constructs implanted for 4 and 8 weeks, which hypothetically has superior cartilaginous development.

\section{Materials and methods}

The study was conducted after receiving the ethical approval from the animal and research ethics committee of our university. The project approval number from Universiti Kebangsaan Malaysia was FF-307-2009.

\section{Tantalum preparation}

All scaffolds were prepared from $2 \mathrm{~cm}$ in diameter and $10 \mathrm{~cm}$ length of Zimmer tantalum screw using Machine
Wire Cut (Hitachi, H-Cut 203 M20) in thickness of $0.5 \mathrm{~mm}$ and Milling Machine Cut to make holes $\varnothing 1.0$ on the both surface of tantalum (Figure 1).

\section{Chondrocyte cell preparation}

Six New Zealand white rabbits age 2 months old and weighting 2.0-2.3 kilograms were used as experimental animals. Blood was taken to get autologous plasma and serum before the animal was sacrificed with overdosage of phenobarbital. Full-thickness cartilage was harvested from the knee, hip joints, and patella articular surface under aseptic technique. Each cartilage was separated from the perichondrium and subchondrium bone, minced into small pieces $\left(1 \mathrm{~mm}^{3}\right)$, washed with Dulbecco phosphate buffer saline (DPBS; pH 7.2; Gibco, Grand Island, NY, USA) containing $100 \mu / \mathrm{ml}$ penicillin and $100 \mu / \mathrm{ml}$ streptomycin (PBS, Gibco). Finally, the samples were washed with DPBS one more time. Cartilages were digested using $0.3 \%$ collagenase type II (Gibco) in a shaker incubator (Stuart Scientific, Redhill, UK) at $37^{\circ} \mathrm{C}$ for $90 \mathrm{~min}$. Samples were centrifuged $(500 \times g)$ for $10 \mathrm{~min}$ to get the cell pellet. The supernatant was removed and the cell pellet was washed with $15 \mathrm{ml}$ DPBS to remove the remaining enzyme. The sample was centrifuged for $10 \mathrm{~min}$ to get the final pellet cells. Isolated chondrocytes were

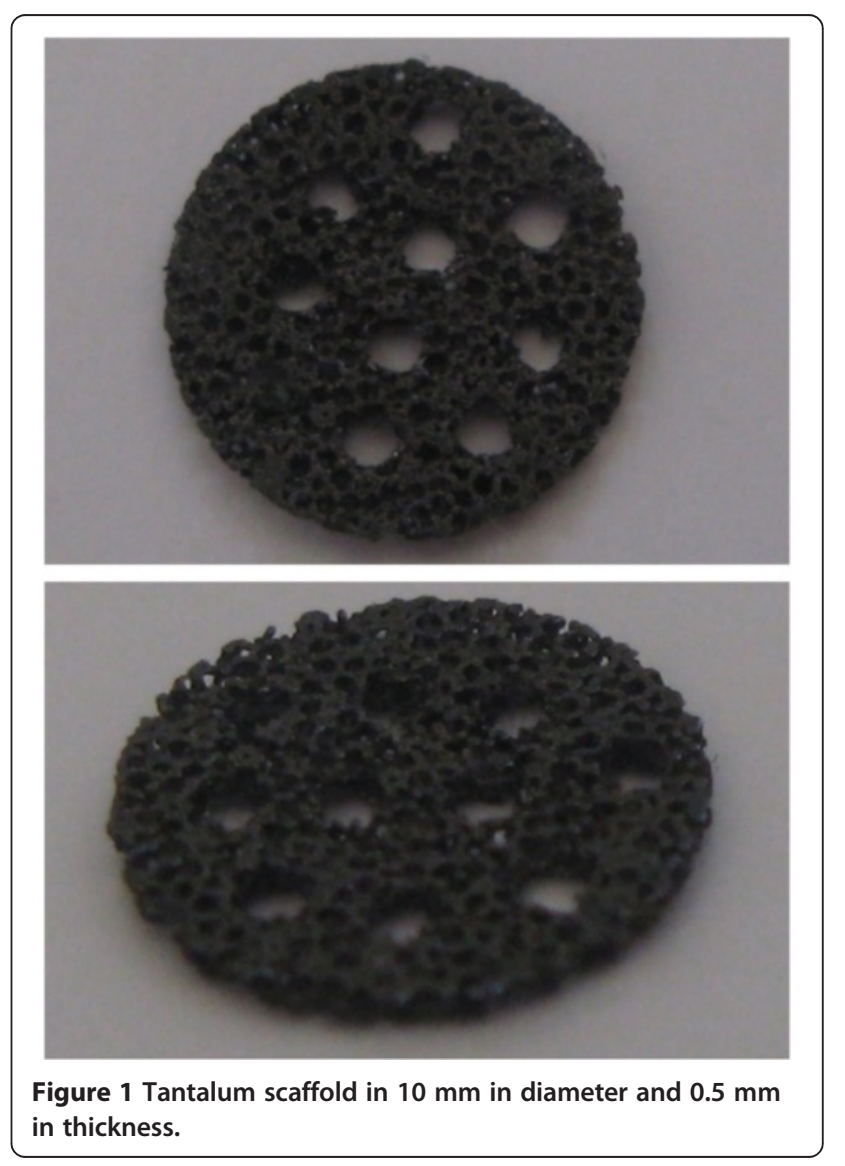


seeded in six well plates containing the culture medium (Ham's F12 and Dulbecco's modified medium 1:1+1\% ascorbic acid $+10 \%$ autologous serum + antibiotic/antimycotic $+1 \%$ glutamine). All cultures were maintained in $5 \%$ $\mathrm{CO}_{2}$ incubator (Jouan, Duguay, Trouin, $\mathrm{SH}$ ) at $37^{\circ} \mathrm{C}$ with every 3 days medium change. Once confluence, the primary cultures were trypsinized using trypsin-EDTA $0.125 \%$ (Gibco). The cells pellet were then cultured in large-scale $175 \mathrm{~cm}^{2}$ culture flask (Falkon, Franklin Lake, NJ, USA) at a density of $5,000 \mathrm{cells} / \mathrm{cm}^{2}$. Chondrocyte morphologic features were examined every day using inverted light microscope (Olympus, Shinjukuku, Tokyo). Upon confluence, the cells were trypsinized and mix with plasma before put on to the tantalum. Fibrin polymerization took place after $\mathrm{CaCl}_{2}$ solution was added into the mixture. The cell-fibrintantalum constructs were maintained for 3 days in the culture before implantation. It was cultured in the same medium for cell expansion, in the six-well dishes and maintained in the $\mathrm{CO}_{2}$ incubator.

\section{Construct implantation}

Under aseptic technique, surgery was performed under sedation. Cocktail drug which consist of ketamine, xylazine, and zoletil was given according to body weight intramuscular. Surgical incision was made at the dorsum of nude mice, and two constructs were implanted on the left and right side of the dorsum (Figure 2). The skin was then sutured using $6 / 0$ vicryl (12 complexes totally at six mice). Care of the nude mice was carried out following the animal facility guideline of the Animal Unit, UKM.

\section{Harvest of composite}

Three mice were sacrificed after 4 weeks and another three mice were sacrificed after 8 weeks to remove the constructs.

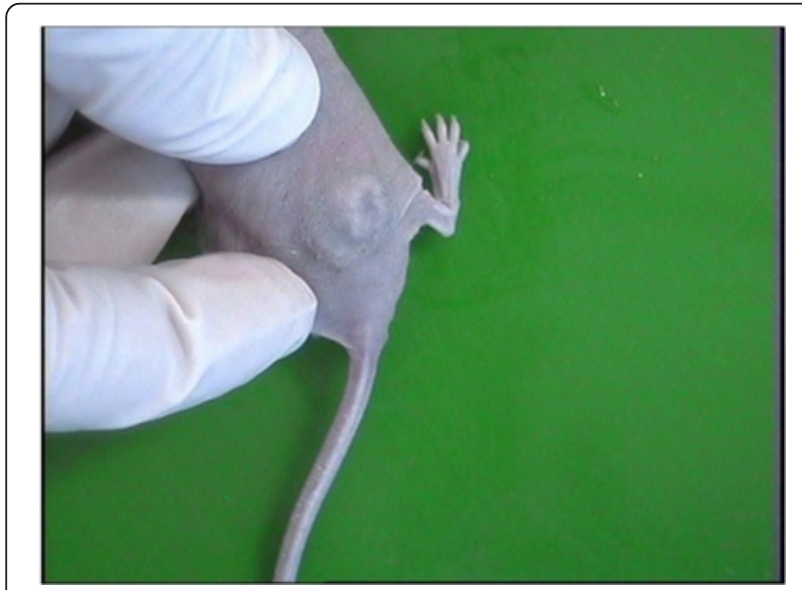

Figure 2 Construct implanted over dorsum of mice.

\section{Histological and biochemical assessment}

The obtained cartilage underwent histology and biochemical evaluation. Constructs were fixed in $10 \%$ formalin for $24 \mathrm{~h}$ at $4^{\circ} \mathrm{C}$ and processed using standard histological technique which finally embedded in paraffin. The tissues were cross sectioned ( $5 \mu \mathrm{m}$ thick) and stained with hematoxylin and eosin, and Alcian blue according to standard procedures. For biochemical assessment, the amount of glucosaminoglycans (GAGs) was measured using the dimethylmethylene blue (DMMB) assay (12) and the total amount of GAGs per dry weight of formed cartilage $(\mu \mathrm{g} / \mathrm{ml} / \mathrm{mg})$ was recorded.

\section{GAG quantification}

For quantitative measuring of GAGs, the total GAGs content of cell/polymer constructs was determined using papain digestion and the dimethylmethylene blue dye method. Samples were lyophilized for $24 \mathrm{~h}$ and then digested under sterile conditions with papain type III (Sigma) at $125 \mathrm{mg} / \mathrm{ml}$ in a buffer of $0.1 \mathrm{M} \mathrm{NaH}_{2} \mathrm{PO}_{4}$, $5 \mathrm{mM}$ methylenediaminetetraacetic acid, and $5 \mathrm{mM}$ cysteine hydrochloride at $\mathrm{pH} 7.0$ overnight at $60^{\circ} \mathrm{C}$ before the dye was added. Dimethylmethylene blue stock solution was made using dimethylmethylene blue, sodium chloride, glycine, sodium aziade in $1 \mathrm{~N}$ hydrochloride, and water. A spectrophotometer set at a wavelength of $520 \mathrm{~nm}$ was used to measure the optical density of the digested samples. Glycosaminoglycan was measured and reported in micrograms per milliliter per milligram of dry weight tissue.

\section{Immunohistochemistry}

Formalin-fixed tissues were sectioned and treated with proteinase $\mathrm{K}$ at $37^{\circ} \mathrm{C}$ for $60 \mathrm{~min}$ before washed three times with tris buffered saline (TBS, DAKO Cytomation). The sections were then treated with peroxidase block at $37^{\circ} \mathrm{C}$ for 10 min prior to incubation with antibody. Two antibodies were used, anti-type I and antitype II collagen were diluted 1:150 with diluent (DAKO Cytomation) and applied to different sections for $40 \mathrm{~min}$ at $37^{\circ} \mathrm{C}$. After washing with $\mathrm{TBS}$, the sections were reacted with horseradish peroxidase (HRP) for $40 \mathrm{~min}$ at $37^{\circ} \mathrm{C}$. After washing again with TBS, the signal was finally visualized as a brown reaction product from the peroxidase substrate $3,3^{\prime}$-diaminobenzidine (DAB).

\section{Quantitative gene expression by real-time PCR}

Total RNA was extracted from removed tissue engineered using TRI reagent (Molecular Research Center, Cincinnati) according to the manufacturer. Cartilage differentiation (type II collagen, SOX9 transcription factor, and aggrecan core protein), dedifferentiation (type I collagen), and hypertrophy (type $\mathrm{X}$ collagen) gene expression level was quantified by real-time PCR technique. Primer sequence used was 
designed with Primer 3 software based on the GeneBank database sequences corresponding to the specific gene Accession Number. The reaction kinetic and specificity of each primer set was verified with standard curve and melting profile. The quantitative RT-PCR protocol was performed in a Bio-Rad iCycler with profile of cDNA synthesis for $30 \mathrm{~min}$ at $50^{\circ} \mathrm{C}$, pre-denaturation for $2 \mathrm{~min}$ at $94^{\circ} \mathrm{C}$ and PCR amplification for 38 cycles with $10 \mathrm{~s}$ at $94^{\circ} \mathrm{C}, 10 \mathrm{~s}$ at $60^{\circ} \mathrm{C}$, and $30 \mathrm{~s}$ at $72^{\circ} \mathrm{C}$. This series of cycles was followed by melt curve analysis to check the reaction specificity. The data was analyzed using Bio-Rad iCycler software. The expression level of each targeted gene was normalized to the house keeping gene - GAPDH.

\section{Statistical analysis}

Data for GAGs amount in each construct at all three environments (in vitro, in vivo, 4 and 8 weeks) were collected from 16 samples. Values were presented as mean \pm standard error of mean (SEM). ANOVA and Student's $t$ test were used to compare data between groups. Differences were considered significant when $p<0.05$. Data collected from quantitative parameter was analyzed using independent $t$ test or Mann-Whitney test. Values were presented as mean \pm SEM. Differences at $5 \%$ level were considered significant. All analyses were performed using SPSS 10.0 software.

\section{Results}

\section{Cellular morphology and construct gross appearance}

In monolayer culture, chondrocytes exhibited small and polygonal shape and they continued to proliferate and reached confluency after 1 week (Figure 3). After construct implantation, all nude mice survived without any clinical signs of morbidity or mortality. Grossly, the constructs demonstrated stable form of implant with no signs of tissue reaction. After 4 and 8 weeks implantation, three nude mice were sacrificed at 4 weeks and another three nude mice at 8 weeks to harvest the constructs. Tissueengineered cartilage appeared white, smooth, glistening, and felt to be firm, resisting to compression resembling a normal hyaline cartilage (Figure 4).

\section{Histological results}

The histological results at day 1 in vitro and 4 weeks and 8 weeks in vivo constructs were variable. In vitro samples demonstrated immature lacunae cells with scanty basophilic matrix background. In vivo samples at 4 weeks implantation had more evenly distributed lacunae cells, but immature with reactive nucleus in the tissue. Samples at 8 weeks implantation revealed evenly distributed lacunae embedded within a basophilic matrix (Figure 5). At both 4 and 8 weeks, the tantalum remains intact and incorporated as a composite with the cells and fibrin.

Alcian blue staining as specific staining for proteoglycan showed immature cells with scanty hyalinized matrix background in in vitro samples. Following 4 weeks implantation, the cells appeared rounded in clusters with extracellular matrix-stained blue, indicating production of proteoglycan. In vivo samples at 8 weeks demonstrated abundant mature cells in clusters, with extensive staining throughout the extracellular matrix (Figure 6).

\section{GAG quantification of constructs}

A mean amount of GAGs per dry weight of formed tissue in in vitro, 4 weeks in vivo, and 8 weeks in vivo was $47.32 \pm 3.12$, $58.37 \pm 1.28$, and $72.40 \pm 2.72$, respectively (Figure 7). Statistical analysis using ANOVA method showed increasing amount of GAGs between groups from in vitro (day 1 ) to in vivo ( 4 and 8 weeks) which is significant $(p<0.005)$. This demonstrated high-quality cartilage tissue formed with increasing implantation period in the in vivo environment.

Quantitative comparison between in vitro and 4 weeks in vivo construct using Student $t$ test demonstrated significant difference between the total amount of produced GAGs $(p=0.013)$. Comparison of total amount of GAGs per dry weight between 4 and 8 weeks in vivo

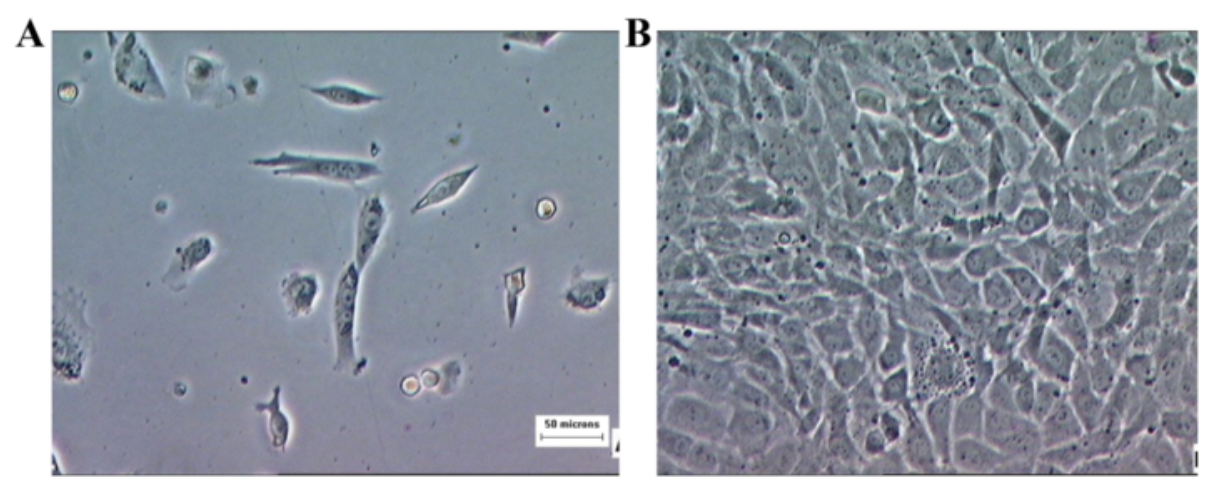

Figure 3 Chondrocytes morphology at primary culture. (A) Small, polygonal shape at early stage. (B) Chondrocytes reached confluency after 1 week in culture. Magnification $\times 200$. 


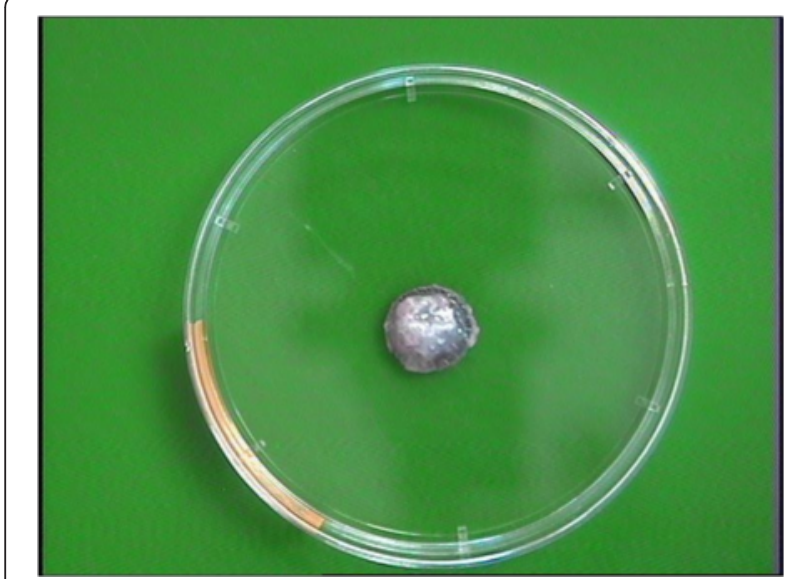

Figure 4 Construct of tantalum-chondrocyte-fibrin after implantation.

demonstrated significant difference as well $(p=0.006)$. Samples at 8 weeks implantation formed more high-quality cartilage with higher amount of GAGs production.

\section{Immunohistochemistry of constructs}

Following implantation, tissue-engineered cartilage showed progression from immature tissues towards maturity by 4 and 8 weeks. By 8 weeks, the histological feature exhibited lacunar being formed with increase in extracellular matrix. In vitro construct exhibited poorly distributed cartilage cells and less lacunar formed. We observed moderate expression towards collagen type I around the underdeveloped pericellular matrix but no expression for collagen type II (Figure 8).

In vivo construct showed strong expression towards collagen type II with brown discoloration pericellular and throughout the matrix. Weak immunopositivity was observed towards collagen type I (Figure 9).

\section{Real-time PCR analysis on the constructs}

Cartilage-associated genes (collagen type II, aggrecan core protein, Sox 9 transcription factor) showed significantly higher expression in in vivo constructs at 4 and 8 weeks compared to in vitro construct. This proved the greater ability of in vivo tissue-engineered cartilage to produce mature cartilage phenotype. However, we observed no significant difference between in vivo constructs at 4 and 8 weeks, except for aggrecan core protein (Figure 10).

Fibrocartilage (collagen type I) and hypertrophic (collagen type X) markers showed moderately high gene expression levels. There was significant difference between in vitro and in vivo constructs at 4 and 8 weeks but no difference was observed between in vivo constructs at the same period (Figure 11).

\section{Discussion}

Areas of research regarding cartilage repair have essentially focused on cultured cells supported in the engineered tissue. The delivery of this tissue is one of the challenges which
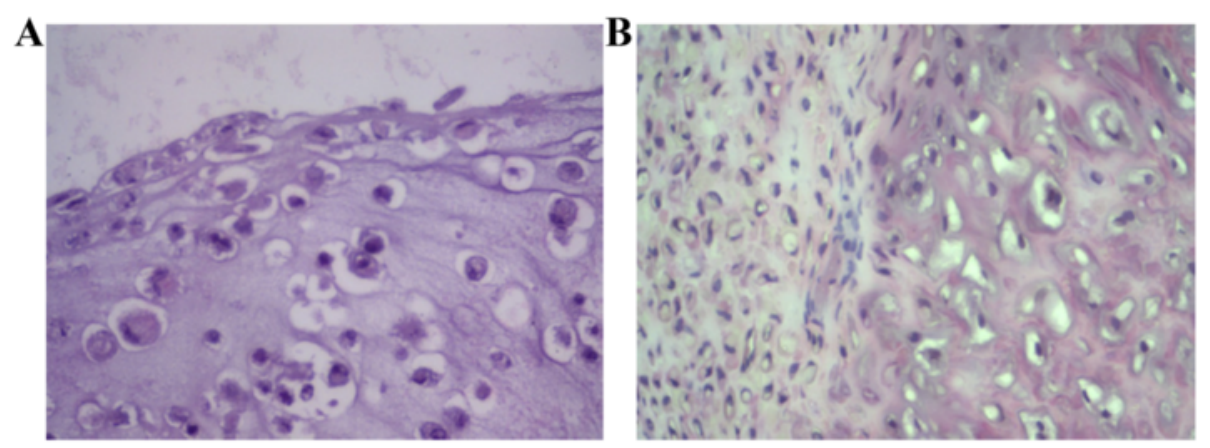

C

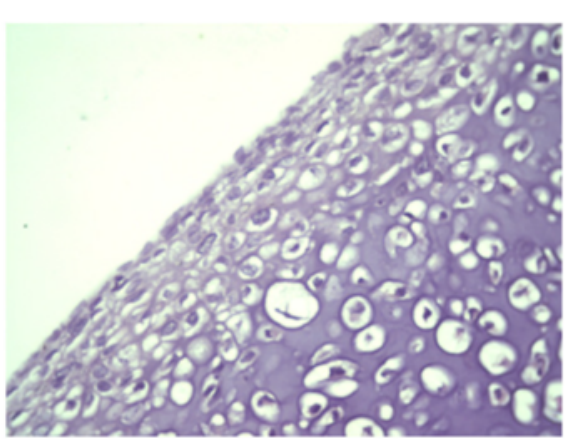

Figure 5 H\&E staining of tissue in in vitro (A), 4 weeks in vivo (B), and 8 weeks in vivo (C). In vitro construct showed immature cells with scanty basophilic background, while both in vivo constructs demonstrated evenly distributed lacunae cells within basophilic matrix. However, 8-week construct exhibited more mature cells throughout extracellular matrix. 

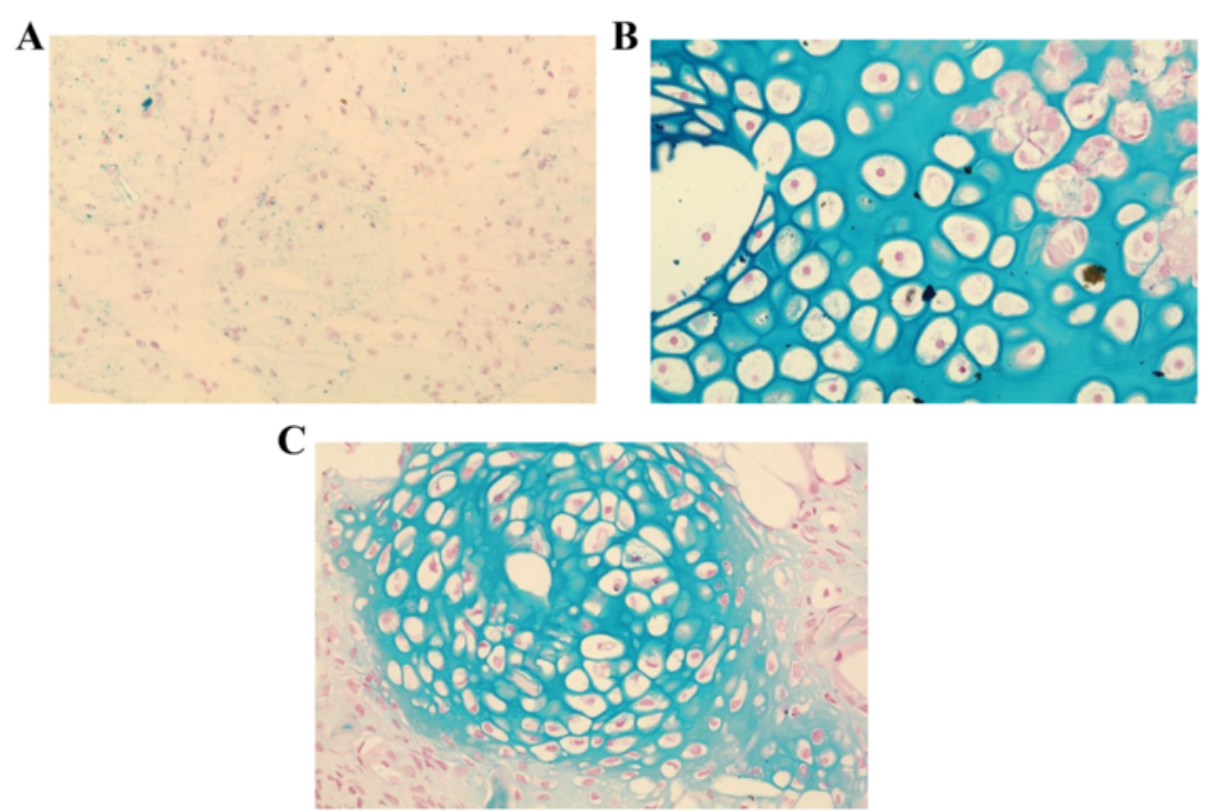

Figure 6 Alcian blue staining for proteoglycan of tissue in vitro (A), 4 weeks in vivo (B), and 8 weeks in vivo (C). Formed tissue obtained from 8 weeks in vivo construct revealed abundant cells in clusters with positive staining throughout the extracellular matrix compared to 4 weeks in vivo and in vitro construct.

include developing an appropriate scaffold and adhesive to provide matrix for the cells to grow. The term 'chondroconductive' was described by Gordon et al. and defined as providing a scaffold for the growth of cartilage and supporting structures [17]. They found that porous tantalum is chondroconductive in vitro in dynamic environment. The potential of porous tantalum has been further evaluated by Mardones et al. in the development of cartilage-tantalum composite [18]. In this study, periosteum from rabbits were placed on top of porous tantalum cylinders and cultured under chondrogenic conditions for 6 weeks. The findings show hyalinelike cartilage on the surface of the cylinders while the pores of the scaffold were filled with fibrous fixation. Mechanical testing was also performed which showed properties similar to normal rabbit cartilage. This cartilage from femoral condyles were made into osteochondral plugs and tested against the composite. It showed a stress-strain curve with characteristics typical of normal cartilage responding to a load. These findings have been the basis of further studies to consider cartilage-tantalum composite as an option for resurfacing and arthroplasty procedures. The abovementioned technique has limitation in term of making different thickness of cartilage from periosteum tissue. In the present study, we used fibrin to bind cultured chondrocytes and seeded onto tantalum in order to increase the feasibility of making various thickness of cartilage tissue.

The limitation of the study was the relatively short study period. An animal study by Shao et al. using allogeneic

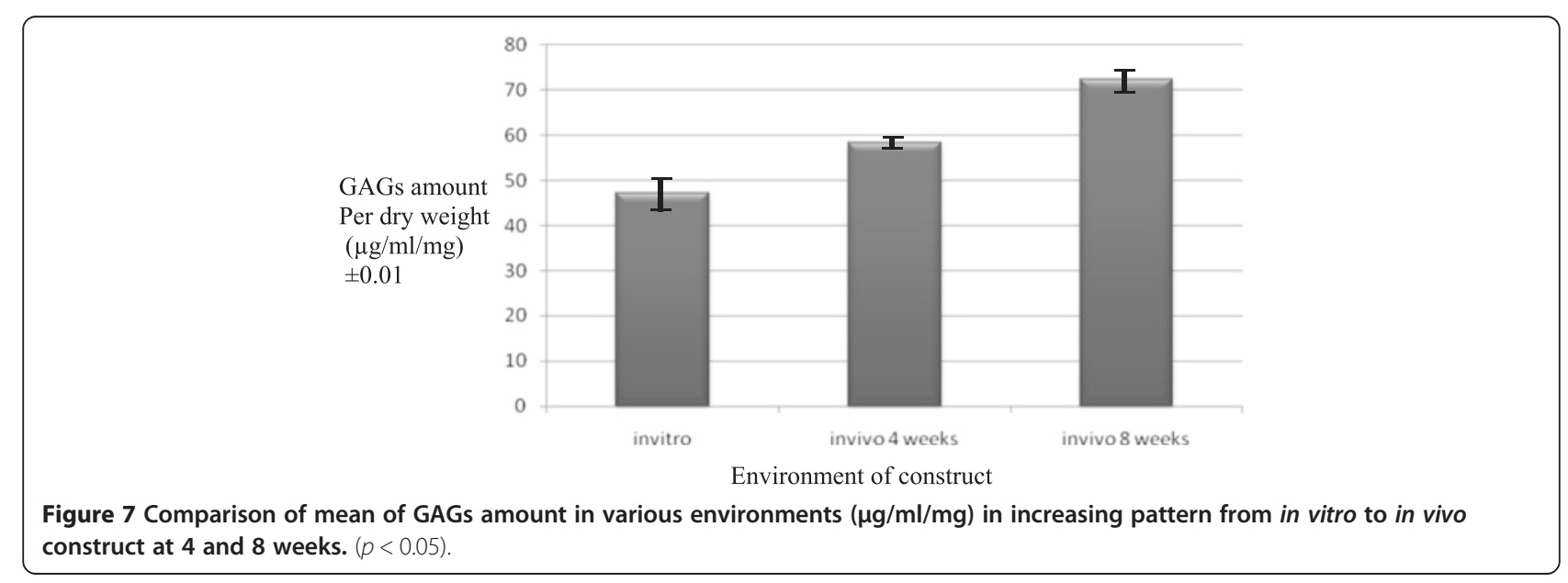



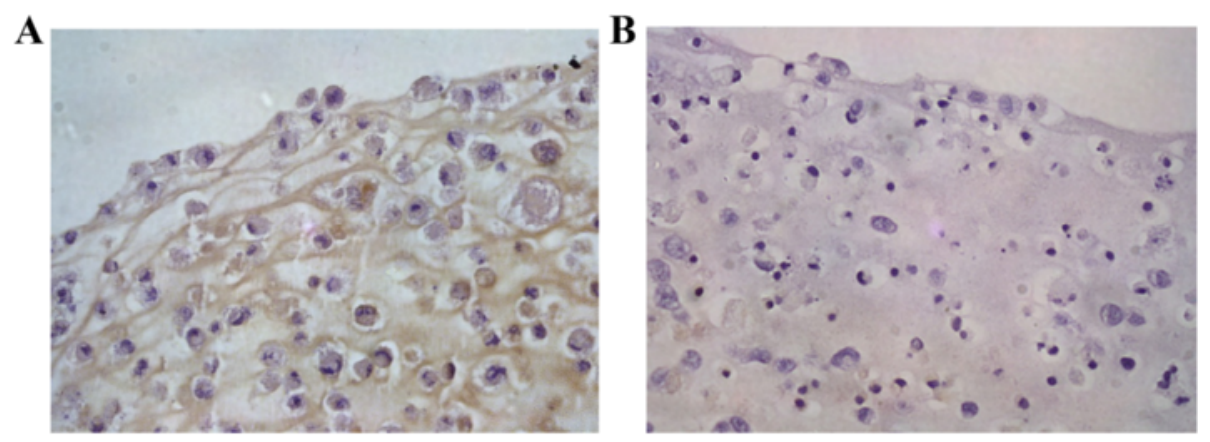

Figure 8 Immunohistochemical staining for in vitro construct shows brownish deposition for localization of collagen type I (A) but no expression for collagen type II (B).

bone marrow mesenchymal stem cells (BMSC) seeded onto fibrin glue matrix and medical-grade polycaprolatone $(\mathrm{mPCL})$ revealed deterioration of the transplant after 6 months, despite early good results [19]. Admittedly, if the present study could have been conducted over the same time period with the previous reported study, we could have compared it better. Furthermore, the subcutaneous environment of our construct on the dorsum of nude mice might not be representative of a true clinical situation where intraarticular environment is involved. Mrosek et al. reported an in vivo study where cylindrical osteochondral defects were created on the medial and lateral condyles of ten rabbits and filled with tantalum/periosteum or poly-epsilon-caprolactone/periosteum biosynthetic composites [20]. Even though subchondral bone regeneration was excellent, neo-cartilage formation from periosteum supported by a scaffold was inconsistent [20]. However, Munirah et al. proved that autologous chondrocyte-fibrin construct (ACFC) promotes early chondrogenesis by inducing hyaline-like cartilage regeneration at 12 weeks postsurgery in a sheep model [16]. Biomechanical testing is also appropriate as the next step for tantalum-chondrocyte-fibrin composite.

In the present study, the tissue-engineered cartilage showed morphological features of polygonal that became spindle-shaped and elongated during monolayer culture. These findings are similar to previous studies, which portrays the dedifferentiation in culture as the cultured chondrocytes lost their phenotype to adopt fibroblastic traits [15,21,22]. Our 2-month results also demonstrated that cultured chondrocytes within the fibrin and tantalum scaffold are able to differentiate and produce hyaline-like cartilage tissue. Histological evaluation of in vivo samples revealed chondroblast and chondrocytes surrounded by matrix containing hyaline. Seeded cell on tantalum in vitro was uniform and homogenous and contained immature chondrocytes with low concentration of GAGs in the hyalinized matrix, while in implanted constructs, the total amount of GAGs per dry weight of tissue significantly increased. This was further proven by strong immunopositivity by immunohistochemistry at 4 and 8 weeks, respectively. It also means that by 2 months, the cartilage has not featured any age-related changes yet. Studies with longer duration need to be done to evaluate the integrity of the cartilage. We also found that cartilage-associated genes (collagen type II, AggC, Sox 9) showed high gene expression after 8 weeks. This supports our hypothesis and suggested that the cartilage composite had produced a good matrix for the chondrocytes to differentiate. Similar findings were reported by previous studies of human articular chondrocytes [15,23].
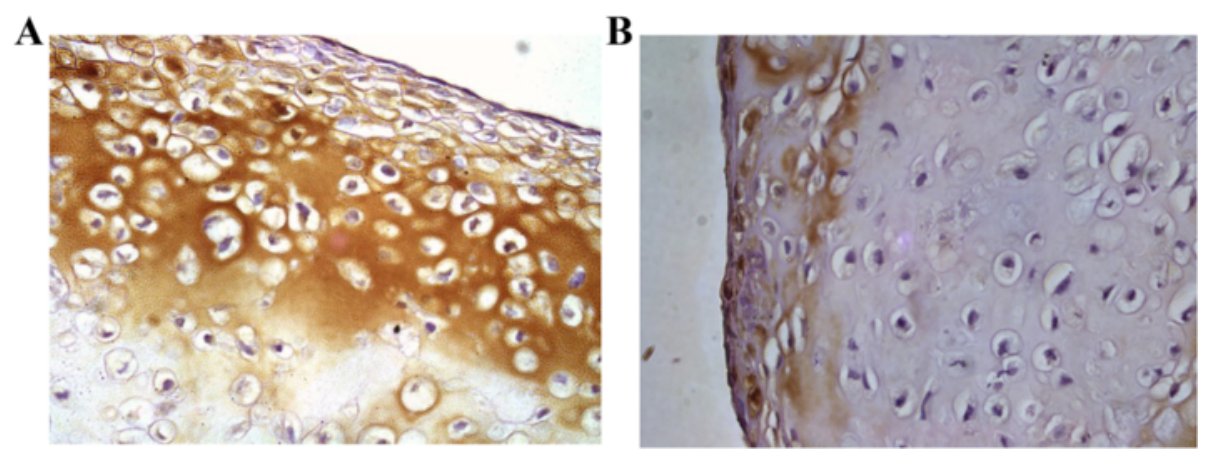

Figure 9 Immunohistochemical staining of in vivo construct shows strong reaction towards collagen type II (A) but weak reaction with collagen type I with brown discoloration extracellularly (B). 


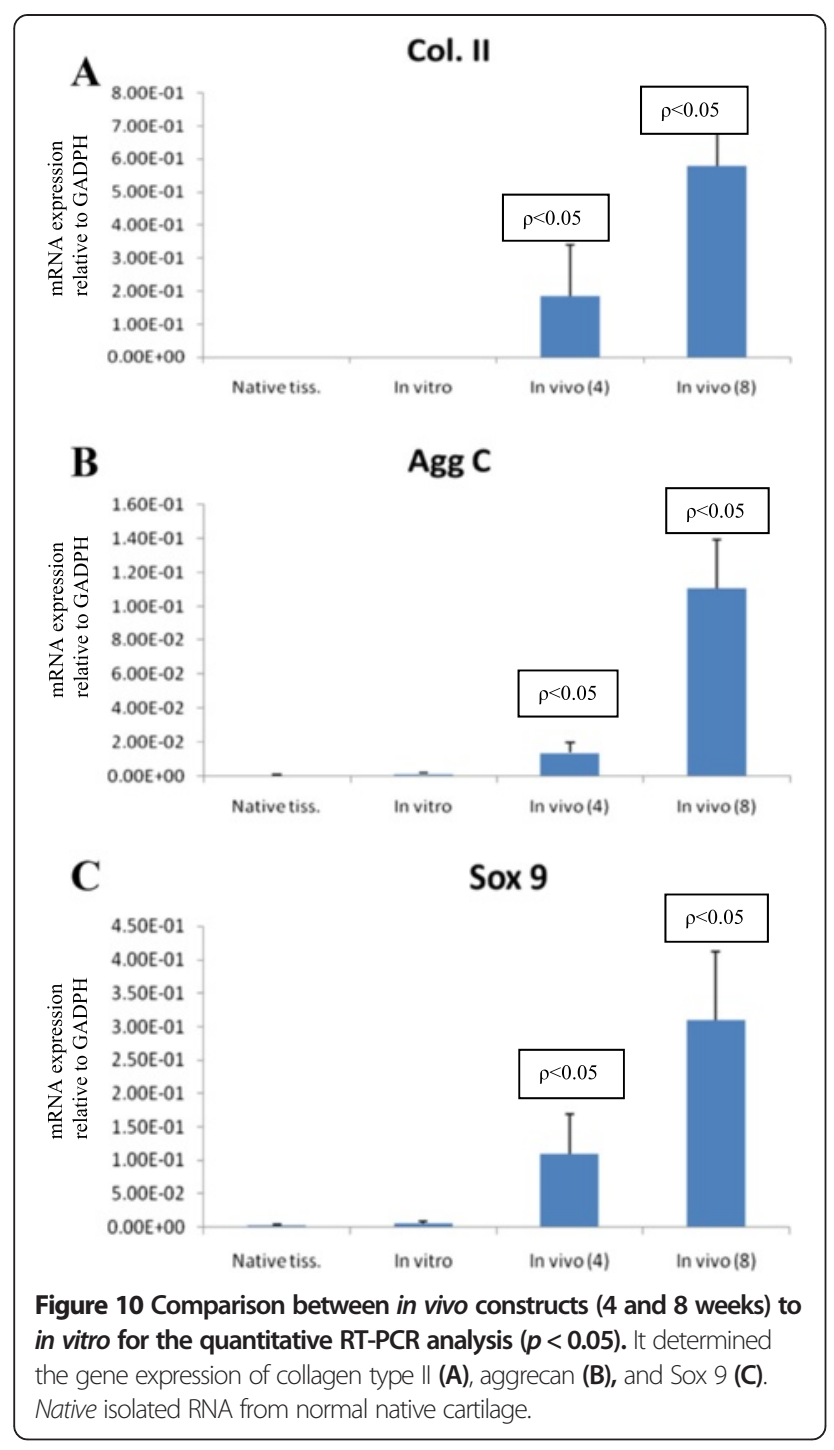

Fibrocartilage and hypertrophic markers even though present showed much lower expression level. Sasano et al. also discovered that chondrocytes synthesize collagen type I and accumulate the protein in the matrix during his study of rat tibial articular cartilage [15,24].

These findings are in accordance with previous studies in proving that autologous chondrocyte and fibrin composite produced good-quality cartilage-like tissue [21,25-32]. In addition, we overcome the concern of fibrin glue detachment and degradation by providing a good scaffold with tantalum. Tantalum usage has been well established in clinical settings due to its biocompatibility and highly interconnected porosity which permits physiologic bone ingrowth and healing [17,33-41]. By 8 weeks, this tantalumchondrocyte-fibrin composite show good promise in providing solution for cartilage defect. Clinically, this cartilage construct may be implanted arthroscopically and remain in situ with a stable scaffold. This advantage offers the option
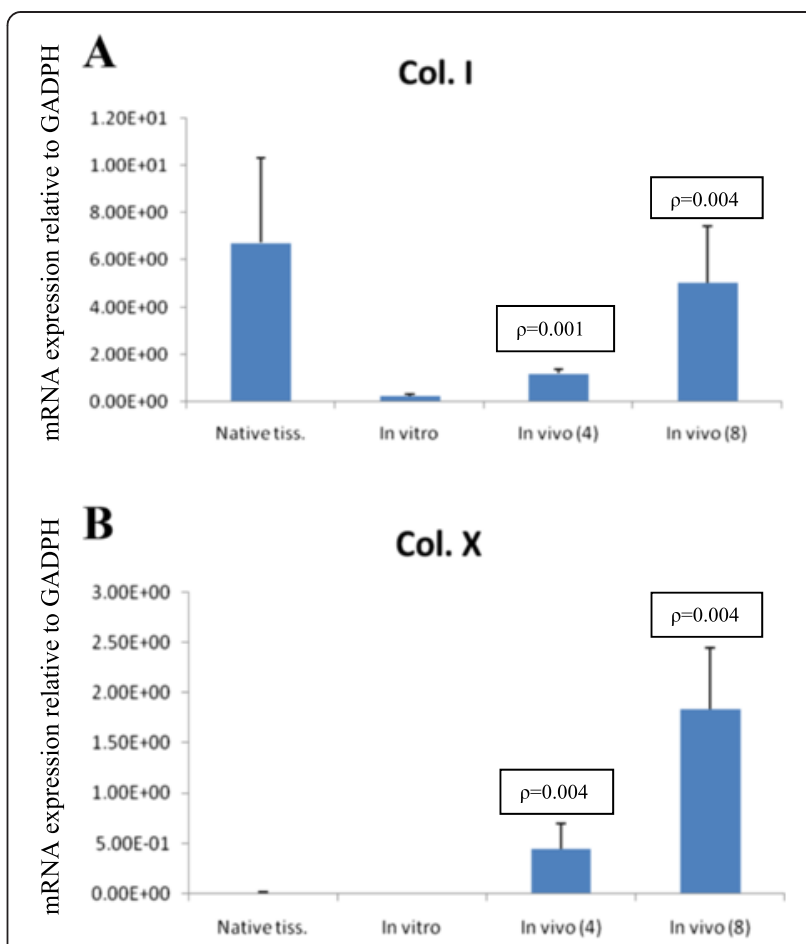

Figure 11 Comparison between in vivo constructs ( 4 and 8 weeks) to in vitro for the quantitative RT-PCR analysis $(p<0.05)$ of gene expression of collagen type I (A) and collagen type $\mathrm{X}(\mathrm{B})$. Native isolated RNA from normal native cartilage.

of a single surgery without the use of a periosteal patch which can be unstable.

\section{Conclusion}

We showed that tantalum scaffold with fibrin as cell carrier promotes cellular proliferation and cartilaginous tissue ormation of rabbit articular chondrocytes. Engineered cartilage resulted from in vivo-implanted construct demonstrated high-quality hyaline-like tissue by histological and biochemical assessment, GAG quantification, immunohistochemistry, and real-time PCR. This early results highlight the potential of tantalum-chondrocyte-fibrin composite in treatment of cartilage defect.

\section{Competing interests}

The authors declare that they have no competing interests.

\section{Authors' contributions}

$\mathrm{KJ}$ carried out the animal studies, participated in the laboratory assessments, and drafted the manuscript. SLN carried out the histological and biochemical assessments, immunohistochemistry, PCR analysis, and statistical analysis. SJ participated in the cell preparation and harvest of composite. NHY conceived of the study and participated in the design of the study. KHC conceived of the study, participated in its design and coordination, and helped to draft the manuscript. All authors read and approved the final manuscript.

\section{Acknowledgements}

The source of funding for the study was from the Research Fund of Universiti Kebangsaan Malaysia. We would like to thank Professor Srijit Das for his help and contribution in completing the manuscript. 


\section{Author details}

'Department of Orthopaedic and Traumatology, Faculty of Medicine, Universiti Kebangsaan Malaysia, Jalan Yaacob Latiff, Bandar Tun Razak, 56000 Cheras, Kuala Lumpur, Malaysia. ${ }^{2}$ Department of Physiology, Faculty of Medicine, Universiti Kebangsaan Malaysia, Jalan Raja Muda Abdul Aziz, 50300 Kuala Lumpur, Malaysia.

\section{Received: 11 September 2014 Accepted: 14 January 2015} Published online: 07 February 2015

\section{References}

1. Widuchowski W, Widuchowski J, Trzaska T. Articular cartilage defects: study of 25,124 knee arthroscopies. Knee. 2007;14:177-82

2. Arden N, Nevitt MC. Osteoarthritis: epidemiology. Best Pract Res Clin Rheumatol. 2006;20:3-25.

3. Duffy GP, Trousdale RT, Stuart MJ. Total knee arthroplasty in patients 55 years old or younger. 10- to 17-year results. Clin Orthop Relat Res. 1998;356:22-7

4. Duffy GP, Crowder AR, Trousdale RR, Berry DJ. Cemented total knee arthroplasty using a modern prosthesis in young patients with osteoarthritis. J Arthroplasty. 2007;22(6 Suppl 2):67-70.

5. Hofmann AA, Heithoff SM, Camargo M. Cementless total knee arthroplasty in patients 50 years or younger. Clin Orthop Relat Res. 2002:404:102-7.

6. Sheng PY, Konttinen L, Lehto M, Ogino D, J"amsen E, Nevalainen J, et al. Revision total knee arthroplasty: 1990 through 2002. A review of the Finnish arthroplasty registry. J Bone Joint Surg Am. 2006;88:1425-30.

7. Wright TM, Maher SA. Current and novel approaches to treating chondral lesions. J Bone Joint Surg. 2009;91(1):120-5.

8. Shelbourne KD, Jari S, Gray T. Outcome of untreated traumatic articular cartilage defects of the knee: a natural history study. J Bone Joint Surg. 2003;85 suppl 2:8-16.

9. Kakarlapudi TK, Bickerstaff DR. Articular cartilage lesions of the knee: putting the jigsaw puzzle together. Curr Orthop. 2002;16(2):139-50.

10. Brittberg M, Lindahl A, Nilsson A, Ohlsson C, Isaksson O, Peterson L. Treatment of deep cartilage defects in the knee with autologous chondrocyte transplantation. N Engl J Med. 1994;331(14):889-95.

11. Brittberg M, Tallheden T, Sjögren-Jansson B, Lindahl A, Peterson L. Autologous chondrocytes used for articular cartilage repair: an update. Clin Orthopaedics. 2001;391:337.

12. Gortz S, Bugbee WD. Allografts in articular cartilage repair. J Bone Joint Surg. 2006;88(6):1374.

13. Knutsen G, Drogset JO, Engebretsen L, Grøntvedt T, Isaksen V, Ludvigsen TC. A randomized trial comparing autologous chondrocyte implantation with microfracture. Findings at five years. J Bone Joint Surg. 2007;89(10):2105.

14. O'Driscoll SW. Current concepts review: the healing and regeneration of articular cartilage. J Bone Joint Surg. 1998;80(12):1795-812.

15. Sha'ban M, Soon HK, Ruszymah BH, Khang G. Fibrin and poly(lactic-co-glycolic acid) hybrid scaffold promotes early chondrogenesis of articular chondrocytes: an in vitro study. J Orthop Res. 2008;3:17.

16. Munirah S, Samsudin OC, Chen HC, Sharifah SH, Aminuddin BS, Ruszymah $\mathrm{BH}$. Articular cartilage restoration in load-bearing osteochondral defects by implantation of autologous chondrocyte-fibrin constructs: an experimental study in sheep. J Bone Joint Surg Br. 2007:89(8):1099.

17. Gordon WJ, Conzemius MG, Birdsall E, Wannemuehler Y, Mallapragada S, Lewallen DG, et al. Chondroconductive potential of tantalum trabecular metal. J Biomed Mater Res. 2005;75(2):229-33.

18. Mardones RM, Reinholz GG, Fitzsimmons JS, Zobitz ME, An KN, Lewallen DG, et al. Development of a biologic prosthetic composite for cartilage repair. Tissue Eng. 2005;11(9-10):1368-78.

19. Shao XX, Hutmacher DW, Ho ST, Goh JC, Lee EH. Evaluation of a hybrid scaffold/cell construct in repair of high-load-bearing osteochondral defects in rabbits. Biomaterials. 2006;27(7):1071-80

20. Mrosek EH, Schagemann JC, Chung HW, Fitzsimmons JS, Yaszemski MJ, Mardones RM, et al. Porous tantalum and poly-epsilon-caprolactone biocomposites for osteochondral defect repair: preliminary studies in rabbits. J Orthop Res. 2010;28(2):141-8.

21. Idrus R, Chua KH, Munirah S, Noruddin N, Aminuddin BS. Tissue engineered cartilage with different human chondrocyte sources: articular, auricular and nasal septum. Med J Islamic World Acad Sci. 2005;15(1):5-12.
22. Ishak MF, Chua KH, Asma A, Saim L, Aminuddin BS, Ruszymah BH, et al. Stem cell genes are poorly expressed in chondrocytes from microtic cartilage. Int J Pediatr Otorhinolaryngol. 2011;75:835-40.

23. Munirah S, Kim SH, Ruszymah BH, Khang G. The use of fibrin and poly (lactic-co-glycolic acid) hybrid scaffold for articular cartilage tissue engineering: an in vivo analysis. Eur Cell Mater. 2008;15:41-52.

24. Sasano Y, Furusawa M, Ohtani H, Mizoguchi I, Takahashi I, Kagayama M. Chondrocytes synthesize type I collagen and accumulate the protein in the matrix during development of rat tibial articular cartilage. Anat Embryol. 1996;194(3):247-52.

25. Azmi B, Aminuddin BS, Sharaf I. The significance of using pooled human serum in human articular cartilage tissue engineering. Med J Malaysia. 2004:59:13.

26. Chua KH, Aminuddin BS, Fuzina NH, Ruszymah BH. Interaction between insulin-like growth factor-1 with other growth factors in serum depleted culture medium for human cartilage engineering. Med J Malaysia. 2004:59:7.

27. Chua KH, Aminuddin BS, Fuzina NH, Ruszymah BH. Human serum provided additional values in growth factors supplemented medium for human chondrocytes monolayer expansion and engineered cartilage construction. Med J Malaysia. 2004:59:194.

28. Chua KH, Aminuddin BS, Fuzina NH, Ruszymah BH. Insulin-transferrinselenium prevent human chondrocyte dedifferentiation and promote the formation of high quality tissue engineered human hyaline cartilage. Eur Cell Mater. 2005;9(9):58-67.

29. Farah Wahida I, Aminuddin BS, Munirah S, Chua KH, Fuzina NH, Isa MR, et al. Gene expression characteristic in human auricular cartilage tissue engineering. Med J Malaysia. 2004:59:190.

30. Munirah S, Aminuddin BS, Chua KH, Fuzina NH, Isa MR, Ruszymah BH. Tissue engineered human articular neocartilage using serial expanded chondrocytes. Med J Malaysia. 2004;59:9.

31. Nur Adelina AN, Aminuddin BS, Munirah S, Chua KH, Fuzina NH, Saim L, et al. Phenotypic expression of collagen type II and collagen type I gene in monolayer culture of human auricular chondrocytes. Med J Malaysia. 2004:59:188.

32. Saim L, Aminuddin BS, Munirah S, Chua KH, Izuddin Fahmy A, Fuzina NH et al. Formation of tissue-engineered human auricular cartilage via tissue engineering technique for future use in ear surgery. Med J Malaysia. 2004;59:192.

33. Bobyn JD, Stackpool GJ, Hacking SA, Tanzer M, Krygier JJ. Characteristics of bone ingrowth and interface mechanics of a new porous tantalum biomaterial. J Bone Joint Surg Br. 1999:81(5):907-14.

34. Cohen R. A porous tantalum trabecular metal: basic science. Am J Orthop. 2002;31(4):216-7.

35. Garbuz DS, Hu Y, Kim WY, Duan K, Masri BA, Oxland TR, et al. Enhanced gap filling and osteoconduction associated with alendronate-calcium phosphate-coated porous tantalum. J Bone Joint Surg. 2008;90(5):1090

36. Levine B, Sporer S, Della Valle CJ, Jacobs JJ, Paprosky W. Porous tantalum in reconstructive surgery of the knee: a review. J Knee Surg. 2007;20(3):185-94.

37. Long WJ, Scuderi GR. Porous tantalum cones for large metaphyseal tibial defects in revision total knee arthroplasty: a minimum 2-year follow-up. J Arthroplasty. 2008;24(7):1086-92

38. Macheras G, Kateros K, Kostakos A, Koutsostathis S, Danomaras D, Papagelopoulos PJ. Eight- to ten-year clinical and radiographic outcome of a porous tantalum monoblock acetabular component. J Arthroplasty. 2008;24(5):705-9.

39. Malkani AL, Price MR, Crawford 3rd CH, Baker DL. Acetabular component revision using a porous tantalum biomaterial: a case series. J Arthroplasty. 2008;24(7):1068-73.

40. Meneghini RM, Lewallen DG, Hanssen AD. Use of porous tantalum metaphyseal cones for severe tibial bone loss during revision total knee replacement. Surgical technique. J Bone Joint Surg Am. 2009;91(2):131-8.

41. Patil N, Lee K, Goodman SB. Porous tantalum in hip and knee reconstructive surgery. J Biomed Mater Res B Appl Biomater. 2009:89(1):242-51. 